\title{
Rostral cuneiform nucleus and the defense reaction: Direct and indirect midbrain-medullary serotonin mechanisms in baroreflex inhibition
}

\author{
Florence Netzer ${ }^{1}$ and Caroline Sévoz-Couche ${ }^{1}$ \\ ${ }^{1} \mathrm{UMR}_{S} 1158$
}

October 6, 2020

\begin{abstract}
Background and Purpose: The activation of the defense reaction inhibits the baroreflex response through the B3 and nucleus tractus solitarius (NTS) regions. Our aim was to determine whether and how baroreflex inhibition induced by the disinhibition of the rostral cuneiform nucleus, part of the defense pathway, involves serotonin cells in B3 and 5-HT3 receptors in the NTS. Experimental Approach: We performed immunohistochemistry and anatomical experiments to determine whether raphe serotonin cells expressing Fos were directly targeted by the rostral cuneiform nucleus. The effect of blocking raphe serotonin transmission and NTS 5-HT3 receptors, on cuneiform-induced inhibition of the baroreflex cardiac response, were also analyzed. Key Results: Bicuculline microinjected into the rostral cuneiform nucleus induced an increase of double labeled Fos-5-HT IR cells in both the LPGi and Raphe Magnus. The anterograde tracer Phaseolus vulgaris leucoaggutinin into the rostral cuneiform nucleus revealed a dense projection to the LPGi but not Raphe Magnus. Cuneiform-induced baroreflex inhibition was prevented by B3 injection of 8-OH-DPAT, a specific agonist for 5-HT1A receptors. Cuneiform disinhibition also failed to inhibit the baroreflex bradycardia after microinjection of a 5-HT3 receptor antagonist (granisetron) into the NTS or in 5-HT3 receptor knock-out mice. Conclusion and Implications: In conclusion, the rostral cuneiform nucleus participates in the defense inhibition of the baroreflex bradycardia via direct activation of the LPGi and a relay to the Raphe Magnus, to activate NTS 5-HT3 receptors and inhibit second-order baroreflex neurons. These data bring new insights in primary and secondary mechanisms involved in vital baroreflex prevention during stress.
\end{abstract}

\section{Hosted file}

Netzer et al.pdf available at https://authorea.com/users/364688/articles/485007-rostralcuneiform-nucleus-and-the-defense-reaction-direct-and-indirect-midbrain-medullaryserotonin-mechanisms-in-baroreflex-inhibition

\section{Hosted file}

Figures BJP.pptx available at https://authorea.com/users/364688/articles/485007-rostralcuneiform-nucleus-and-the-defense-reaction-direct-and-indirect-midbrain-medullary-

serotonin-mechanisms-in-baroreflex-inhibition 